\title{
Retour sur « Description du geste technique »
}

\section{Blandine Bril}

\section{OpenEdition}

\section{Journals}

Édition électronique

URL : https://journals.openedition.org/tc/5167

DOI : $10.4000 /$ tc. 5167

ISSN : 1952-420X

\section{Éditeur}

Éditions de l'EHESS

\section{Édition imprimée}

Date de publication : 30 juin 2010

Pagination : 242-244

ISSN : 0248-6016

\section{Référence électronique}

Blandine Bril, «Retour sur « Description du geste technique »», Techniques \& Culture [En ligne], 54-55 2010, mis en ligne le 30 janvier 2013, consulté le 29 septembre 2022. URL : http:// journals.openedition.org/tc/5167 ; DOI : https://doi.org/10.4000/tc.5167 


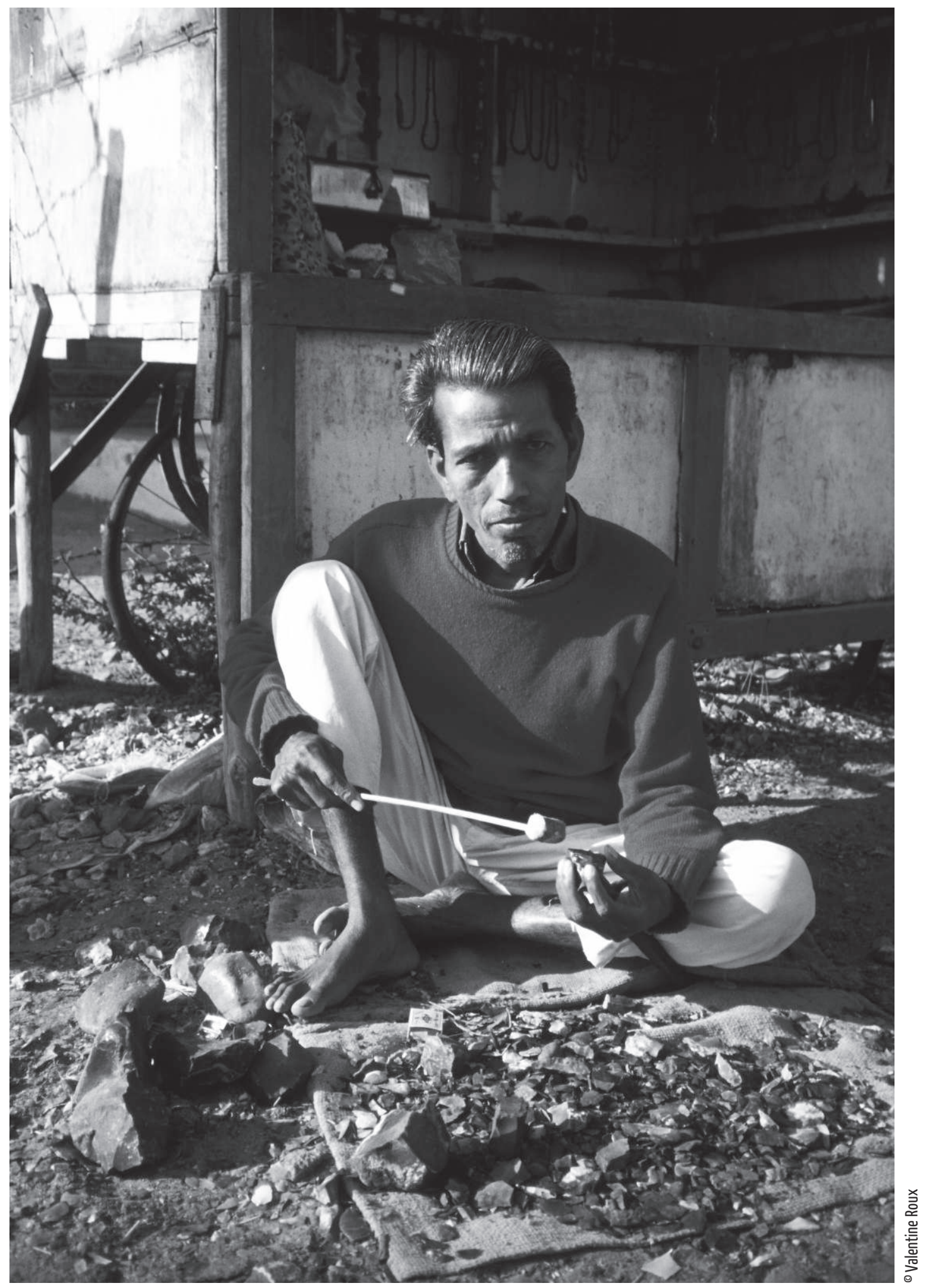




\section{Retour sur}

\section{« Description du geste technique »}

Après 25 ans, que dire de nouveau sur l'analyse du geste technique? En France la référence à l'article de Marcel Mauss sur les techniques du corps reste, en anthropologie, « la » référence, et j'ai parfois le sentiment que le domaine du geste technique, et plus largement des habiletés quotidiennes a peu retenu l'attention dans la communauté francophone. Ayant poursuivi dans cette voie durant toutes ces années je suis arrivée à la conclusion que la question de la «marque culturelle » des habitudes « gestuelles» ne peut trouver de réponse sans un ancrage théorique explicite et fort, qui ne peut venir que de travaux pluridisciplinaires (psychologie du comportement, physiologie du mouvement, biomécanique). Là se trouve la difficulté. En effet on constate généralement une divergence de vue entre sciences humaines et sciences de la vie dans ces domaines et le dialogue est souvent si ce n'est inexistant, du moins difficile. La question du niveau d'analyse différent selon les disciplines est certainement un des nœuds du problème.

J'ai cependant eu la chance de travailler avec des collègues appartenant à différents champs de recherche - psychologie, biomécanique, physiologie, neurosciences, archéologie, primatologie-, et de construire ainsi une problématique qui nous a permis de travailler au niveau des processus en jeu dans la notion d'expertise et de ce qu'elle signifie dans le cas du « geste technique ». Pour cela nous avons retenu les méthodes de recueil de données et d'analyse des sciences du mouvement, créant notre « laboratoire portable ». Nous avons en effet utilisé sur le terrain les moyens d'enregistrement du « geste » généralement employés dans les laboratoires de physiologie du mouvement, de biomécanique ou des sciences du sport (voir les photos 1-5). Cependant la diversité des « gestes techniques » est telle que la question du choix d'outil d'enregistrement du mouvement impose nécessairement une définition précise des objectifs de l'observation. C'est ainsi la formulation de l'objectif qui permettra de définir le niveau d'analyse souhaitable; l'article de 1984 
soulevait à l'époque clairement cette question, de même que la question subsidiaire, chère alors à l'anthropologie: peut-on « décrire » le geste dans sa « totalité »?

Depuis cet article, mon approche de la diversité culturelle du « geste technique » s'est développée selon l'idée que la variabilité culturelle s'exprime par la diversité des objets étudiés, des comportements, mais aussi de l'organisation des contextes de l'apprentissage. La démarche proposée tente de mettre en évidence des analogies fonctionnelles à partir de la diversité culturelle: les observables, eux-mêmes, peuvent être différents, mais les principes de fonctionnement, analogues. Cette perspective permet de mieux cerner les modes de construction des variations culturelles observables de même que les processus de différentiation au cours de l'ontogenèse, c'est-à-dire au cours du développement et de la socialisation de l'enfant. La question posée est alors: comment les contraintes d'ordre anatomique, physiologique, biomécanique, cognitive sont-elles utilisées par l'homme pour construire une motricité qui, en jouant sur une certaine marge de manœuvre, deviendra spécifiquement culturelle? ainsi nous considérons que toute activité technique peut être décrite selon les contraintes «fonctionnelles » de la tâche elle-même. Pour que la tâche soit réussie, ces contraintes doivent être satisfaites quel que soit celui qui la réalise. C'est une fois ces contraintes satisfaites que la culture peut imprimer sa marque à l'activité gestuelle impliquée. Depuis 1984 cette idée a été développée dans de nombreux articles dont quelques uns sont donnés ci-dessous, ainsi qu'un numéro spécial de la revue « Anthropologie des connaissances » consacré au « geste technique ».

Yalé, village dan des Monts Nimba, mission F. Joulian, 1988

Femmes pilant le riz de façon coordonnée mais dans des mortiers distincts.

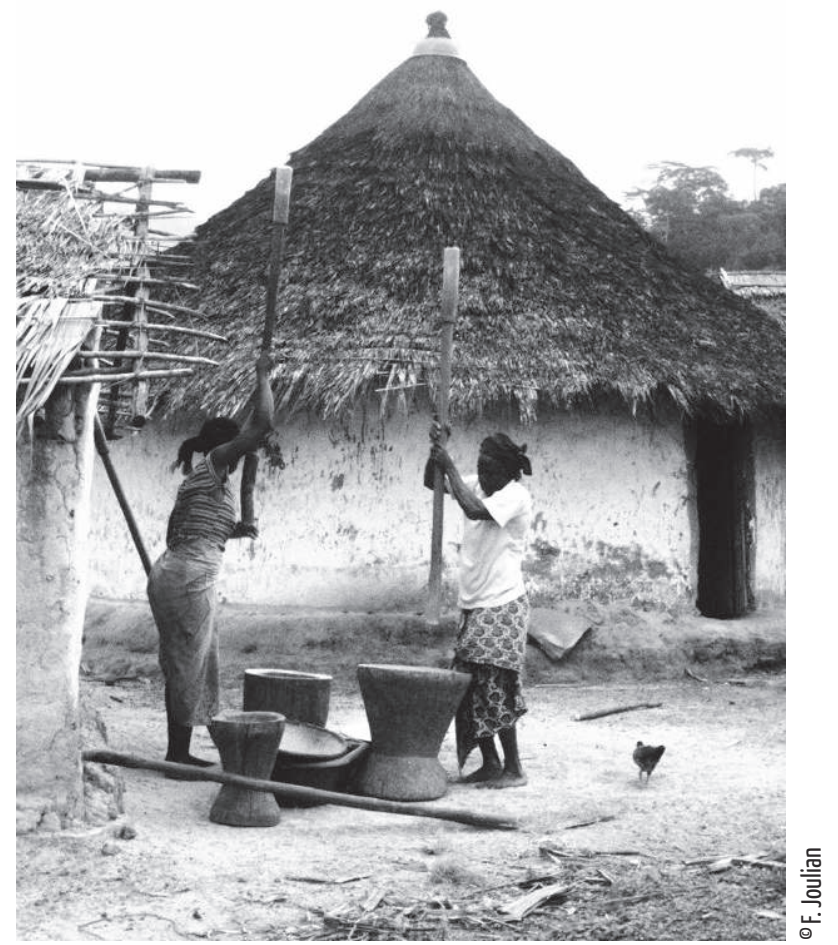

